\title{
Will We Be Harmed, Will It Be Severe, Can We Protect Ourselves? \\ Threat Appraisals Predict Collective Angst (and Its Consequences)
}

\author{
Nassim Tabri ${ }^{1}$ \\ Michael J. A. Wohl ${ }^{1}$ \\ and \\ Julie Caouette ${ }^{1,2}$ \\ ${ }^{1}$ Carleton University, Ottawa, Canada. \\ ${ }^{2}$ John Abbott College, Sainte-Anne-de-Bellevue, Canada.
}

This is a copy of the accepted version of the paper. We have self-archived this version for noncommercial and scholarly purposes only.

The APA $\left(6^{\text {th }}\right.$ ed $)$ style reference for this article is as follows:

Tabri, N., Wohl, M. J. A., \& Caouette, J. (in press). Will we be harmed, will it be severe, can we protect ourselves? Threat appraisals predict collective angst (and its consequences). European Journal of Social Psychology. doi: 10.1002/ejsp.2303

The authors declare that there are no potential conflicts of interest with respect to the research, authorship, and/or publication of this article. This research was supported by a Postdoctoral Fellowship from the Fonds de Recherche du Québec sur la Société et la Culture to Tabri and a Social Sciences and Humanities Research Council of Canada Insight Grant to Wohl. Correspondence concerning this article should be addressed to Michael J. A. Wohl, Department of Psychology, Carleton University, 1125 Colonel By Drive, Ottawa, Ontario, Canada, K1S 5B6. Tel: (902) 520-2600 x 2908, E-mail: michael.wohl@ carleton.ca 


\begin{abstract}
Across four studies, we applied the cognitive model of anxiety (Clark \& Beck, 2010) to explicate the appraisals that elicit collective angst (i.e., concern for the ingroup's future vitality). In Study 1a, consistent with the model, Québécois experienced collective angst when they appraised a threat 1) as likely to harm their group, 2) as severely harming their group, and 3) appraised Québécois as not having efficacy to protect their group. In Study 1b, results were replicated in the context of the realistic threat that Islamic extremists pose to Christian-Lebanese. In Studies $2 \mathrm{a}$ and $2 \mathrm{~b}$, we manipulated the three appraisals and found a similar pattern of results in the context of a potential terrorist attack on American soil by Islamic extremists. Importantly, collective angst mediated the threat appraisal effect on (non-Muslim) Americans' prejudice towards Muslims. The utility of the appraisal model for regulating collective angst (and thus its consequences) are discussed.
\end{abstract}

Key words: collective angst; intergroup conflict; prejudice; threat. 


\section{Will We Be Harmed, Will It Be Severe, Can We Protect Ourselves? Threat Appraisals Predict Collective Angst (and Its Consequences)}

Group members find comfort in the belief that there exists continuity in their group's past, present, and future (Jetten \& Hutchison, 2011; Jetten \& Wohl, 2012; Sani, Bowe, Herrera, Manna, Cossa, Miao, \& Zhou, 2007). This is because a sense of continuity provides existential security (Durkheim, 1951). Yet, social groups are not static; they change — a reality that, when salient, is often perceived as a threat to one's social identity (Riek, Mania, \& Gaertner, 2006) and thus produces distress among group members (Chandler \& Lalonde, 1998; Lampinen, Odegard, \& Leding, 2004). This distress may manifest in collective angst-a group-based emotion that reflects concern for the future vitality of the ingroup (Wohl, Branscombe, \& Reysen, 2010; Jetten \& Wohl, 2012).

Importantly, collective angst originates from perceived extinction threats to one's ingroup. These threats may take the form of realistic extinction threats posed by adversarial outgroups (Wohl et al., 2010; Halperin, Porat, \& Wohl, 2013), but may also take the form of symbolic threats to the group's social identity (e.g., loss of cultural vitality; Wohl, Giguère, Branscombe, \& McVicar, 2011). Halperin and colleagues (2013), for example, found that Israeli Jews experienced collective angst when they were informed that Israel did not have the capability to prevent a nuclear attack from Iran. Likewise, Canadians experienced collective angst when they perceived Canadian distinctiveness from the United States was under threat (Wohl et al., 2011). Whether the threat perceived is realistic or symbolic, the consequence of collective angst is the same - an upswing in support for efforts to strengthen the ingroup (e.g., support for policies that are perceived to be ingroup protective; for a review see Wohl, Squires, \& Caouette, 2012; see Lucas, Rudolph, Zhdanova, Barkho, \& Weidner, 2014). To date, however, 
little is known about the appraisals of intergroup events that are necessary to elicit collective angst. The present research addressed this gap in knowledge by applying the cognitive model of anxiety (Beck, Emery, \& Greenberg, 1985; Clark \& Beck, 2010) to the psychological study of collective angst.

According to Beck and colleagues (1985; Clark \& Beck, 2010), anxiety is a function of three unique appraisals: 1) harm probability (i.e., the extent to which a person appraises a possible future harm as probable), 2) harm severity (i.e., the extent to which a person appraises a future possible harm to be severe), and 3) self-efficacy (i.e., the extent to which a person feels capable of taking action to protect against a future possible harm) (for a similar typology of the appraisals, see Lazarus \& Folkman, 1984). Although they each uniquely predict anxiety, they are also additive in nature - anxiety increases to the extent that harm probability and harm severity are perceived to be high and self-efficacy is perceived to be low. Importantly, prior research has shown that these appraisals elicit stress (e.g., Bandura, 1988; Tomaka, Blascovich, Kelsey, \& Leitten, 1993; Tomaka, Blascovich, Kibler, \& Ernst, 1997; Vlek \& Stallen, 1980). Moreover, empirical support has been found for this model in the treatment of people with anxiety-based disorders (for a review, see Clark \& Beck, 2010).

In the current research, we examined for the first time whether the cognitive model of anxiety can be extended to the group level. That is, we examined whether appraisals known to predict when (and how much) anxiety will be experienced about the future of the personal self can be used to predict when (and how much) anxiety will be experienced about the future of the socially-extended self (i.e., collective angst). Specifically, we tested the idea that collective angst increases to the extent that possible harm to the future vitality of the ingroup (i.e., existential threat; stemming from a current intergroup threat) is highly probable and likely to be severe. 
Moreover, collective angst should increase to the extent that the ingroup is perceived to lack the efficacy needed to protect against the perceived existential threat. We tested this idea in three distinct real-world contexts (the threat English Canada poses to French Canadians, the threat Islamic extremist groups in Syria and Lebanon pose to Lebanese-Christians in Lebanon, and the threat Americans feel from the possibility of terrorism on American soil by the Islamic State of Iraq and Syria).

\section{The Psychology of Collective Angst}

During the Amidah — the central prayer of the Jewish liturgy — the phrase l'dor va-dor ("from generation to generation") is recited. Moreover, this phrase is taught and repeated throughout Jewish education. This is because it expresses a core principle of Judaism: Jews of all generations are inter-connected. Stemming from this principle is a responsibility to transmit the teaching, traditions, and history of Judaism to the next generation to ensure the survival of the Jewish people. Jews are, of course, not the only people who concern themselves with their group's future. Québécois (i.e., French Canadians) are notoriously concerned for the future vitality of French Canadian language and culture. This concern stokes the desire for many Québécois to seek sovereignty for the province of Québec from Canada. Indeed, the former Québec Premier (i.e., leader) Pauline Marois, who is a member of the Parti Québécois (a separatist political party in Québec), stated that “The biggest risk to Québec isn't sovereignty. It is staying in Canada" ("Parti Québécois leader," 2012). Thus, although there is a tendency for group members to perceive their group to be eternal (Reicher \& Hopkins, 2001; Sani et al., 2007), groups can and do perceive threats to that eternality.

Theorists such as Rank (1914) and Sartre (1956) understood that threats to eternality and awareness of eventual nonbeing elicit existential concern or "angst." They argued that a 
consequence of angst is a preoccupation with thwarting or forestalling the source of threat. For example, people who become parents late in life (like the second author) may begin to exercise more or try to eat healthier out of concern that they may not live long enough to see their child reach major life milestones (e.g., graduation, marriage). In a similar way, a growing body of literature has shown that people feel existential concern or collective angst when the social group to which they belong come under existential threat (for a review, see Wohl et al., 2012). For example, group members experience collective angst when they appraise that an event may inflict harm to the unique features of the ingroup that make it distinct from other groups (i.e., a symbolic distinctiveness threat; e.g., language) or the vitality of the group proper (i.e., a realistic threat; Wohl et al., 2010, 2011; also see Dupuis, Porat, \& Wohl, 2015).

In this way, collective angst fits well within the rubric of intergroup emotions theory (IET; Smith, 1993). According to IET, when a person's social identity is salient, people appraise ongoing events based on relevance to their socially extended self (i.e., their ingroup) rather than the individual self. For example, someone can experience anger, fear, or angst, as a result of events that influence an important ingroup — even if the event has no personal influence on the individual. What group-level emotion is experienced corresponds to the appraisals made about the group-relevant event. If the event is appraised as a potential threat to the future vitality of the ingroup, group members will experience collective angst (Wohl et al., 2012). Importantly, grouplevel emotions function to regulate group-relevant or collective behaviour (see Maitner, Mackie, \& Smith, 2006; van Zomeren, Leach, \& Spears, 2012), rather than individual behaviour (Carver, 2015). In the case of collective angst, behaviour is directed toward attempts to secure the future vitality of the ingroup. 
Although there are individual differences in the extent to which group members feel collective angst (see Jetten \& Wohl, 2012; Wohl, Porat, \& Halperin, 2016), appraising a perceived threat to the group's future vitality will elicit this group-based emotion (Lucas, et al., 2014; Mashuri \& Zaduqisti, 2015; Mols \& Jetten, 2014; Wohl, King, \& Taylor, 2014; Wohl et al., 2010). This emotional reaction is distinct from other related group-based emotional reactions, such as collective fear (Wohl \& Branscombe, 2009; Wohl et al., 2010). Indeed, collective angst is theorized to stem from perceiving a potential harm to the ingroup that may occur in the future, whereas collective fear stems from perceiving an immediate and present danger to the ingroup. In response to feeling collective angst, people become motivated to reduce or eliminate the perceived threat to secure a vibrant future for their group (Wohl et al., 2012).

How group members respond as a result of feeling collective angst varies by social and political context. That is, while the emotional goal of collective angst is always to secure the ingroup's future, the specific action taken to achieve this goal depends on what is deemed necessary to protect their group's future. For instance, Québécois who feel collective angst are more apt to support sovereignty from Canada (Wohl et al., 2011). Jewish Israelis who feel collective angst are more likely to support negotiations with the Palestinian Authority, but less likely to do the same with Hamas (Halperin et al., 2013). This is because the Palestinian Authority is perceived to be a willing partner in peace and thus negotiations might facilitate the future survival of Israel. However, Hamas is not perceived to be a partner in peace and thus compromises might facilitate the destruction of Israel. Collective angst can also have more nefarious consequences. For example, Mols and Jetten (2014) showed that leaders of populist right-wing parties in Europe attempt to instil feelings of collective angst in their audience as a means to increase support for harsher treatment of immigrants. Likewise, collective angst among 
Americans increases support for policies that restrict the work opportunities of immigrants (Lucas et al., 2014). Thus, collective angst can have important social and political consequences.

Even though the consequences of collective angst are palpable, the study of its antecedents has been somewhat superficial. That is, extant research has either measured or manipulated group-based existential threat without attention paid to the appraisals that constitute perceptions of such threat, which leads to collective angst (and the actions taken to thwart it). In research presented herein, we address this gap by applying the cognitive model of anxiety (Beck et al., 1985; Clark \& Beck, 2010) to delineate the conditions under which group-based existential threat and thus collective angst will be experienced.

\section{The Antecedents of Collective Angst: Application of the Cognitive Model of Anxiety}

According to the cognitive model of anxiety (Beck et al., 1985; Clark \& Beck, 2010), anxiety is an additive function of the extent to which a person makes three unique appraisals. First, people appraise the probability that the perceived threat will yield harm. High probability estimates are more likely to elicit anxiety than low estimates. Second, appraisals are made regarding the perceived severity of harm that might be experienced if the threat comes to pass. If the harm is appraised as likely to be severe (compared to less severe) anxiety is more likely to be experienced. Lastly, people appraise their ability to effectively contend with the threat (i.e., selfefficacy; Bandura, 1997). The greatest amount of anxiety is likely to be experienced when people appraise the harm probability and harm severity to be high, and their self-efficacy to be low. In contrast, the lowest amount of anxiety is likely to be experienced when people appraise the harm probability and harm severity to be low, and their perceived self-efficacy to protect against harm to be high. As well, some anxiety is likely to be experienced when people appraise the harm probability as high, or the harm severity as high, or their self-efficacy as low. 
In the spirit of the cognitive model of anxiety, we argue that collective angst is most likely to be experienced when members appraise a threat to their group as likely to yield harm, the harm that may be experienced is appraised as likely to be severe, and the ingroup is appraised as lacking the collective efficacy to protect against harm (particularly harm to central aspects of the group; e.g., language and culture). Importantly, the extant collective angst literature provides circumstantial evidence for this supposition. Wohl and Branscombe (2009; see Study 1), for example, found that Americans felt more collective angst when they read a news report indicating that a terrorist attack on American soil by Islamic extremist groups was highly likely compared to Americans who read a news report indicating that the American mission in Iraq was a success and as such that a terrorist attack was unlikely. Thus, collective angst was observed when Americans perceived the probability of an attack against Americans by Islamic extremist groups to be high. Wohl and colleagues (2010; see Study 1), on the other hand, showed that students felt more collective angst when they imagined that their university was destroyed by a tornado compared to students who imagined a typical day on campus. In this way, collective angst was elevated when the severity of potential harm to the ingroup was made salient. Additionally, Halperin and colleagues (2013) reported that collective angst was evoked among Israeli Jews when they read a report suggesting Israel lacked the ability to prevent a nuclear attack by Iran (compared to when Israel was described as having the ability to prevent an Iranian nuclear attack). These results suggest that appraisals of collective efficacy moderates feelings of collective angst. Taken together, it would appear that appraisals of harm probability, harm severity, and collective efficacy are important predictors of collective angst and thus its consequences.

Importantly, a limitation of prior research on collective angst is that the threat 
manipulations used to elicit this emotion often contained content that would apply to two or all three of the aforementioned appraisals (i.e., harm probability, harm severity, and collective efficacy). For example, Wohl and Branscombe (2009; see Study 1) manipulated collective angst by telling participants that a terrorist attack was likely. Thus, although probability of harm was emphasized, appraisals of harm severity were also present. Thus, the unique contribution of any one threat appraisal to the experience of collective angst is currently unknown. Additionally, no empirical study has simultaneously assessed the importance of various intergroup appraisals of threat that elicit collective angst. Herein, we applied the components of the cognitive model of anxiety to the group level in order to assess whether the perceived probability of harm, perceived severity of harm, and collective efficacy of the ingroup to protect the group from harm contribute (uniquely and additively) to the experience of collective angst. In doing so, this will provide insight into the role various appraisals of threat play in eliciting collective emotions-collective angst in particular and its consequences.

\section{Overview of the Current Research}

The main purpose of the present research was to examine the appraisal process that yields perceptions of threat that evoke collective angst. Consistent with the cognitive model of anxiety (Beck et al., 1985; Clark \& Beck, 2010), we hypothesized that appraisals of 1) harm probability,

2) harm severity, and 3) collective efficacy to protect against harm would predict reported collective angst. To test this hypothesis, we conducted four studies. In Studies 1a and 1b, we examined correlations between the aforementioned appraisals and collective angst in two different socio-political contexts. Specifically, Study 1a was conducted with supporters of the Parti Québécois-a separatist political party in Québec, Canada, that is concerned for the future survival of Québécois culture and identity, especially the French language. We examined how 
appraisals of the possible loss of the French language in Québec may relate to feelings of collective angst for Québécois culture and identity. To contrast against the symbolic threat used in Study 1a, Study 1b was conducted with Lebanese-Christians whose existence is currently being threatened by Islamic extremist groups in Lebanon and Syria (see Mroue \& Karam, 2014), such as the Islamic State of Iraq and Syria (ISIS). We examined how appraisals of threat from Islamic extremist groups may relate to feelings of collective angst for the survival of Christian communities in Lebanon.

In Studies $2 \mathrm{a}$ and $2 \mathrm{~b}$, we manipulated the three appraisals to assess whether they regulate feelings of collective angst. In these two last studies, we examined collective angst as it pertains to the threat of a terrorist attack on American soil by ISIS. We also extended our analysis to investigate the consequences of collective angst. Prior research demonstrates that collective angst is a mediating mechanism by which perceived threats to the ingroup facilitate support for harsh treatment of threatening outgroups (Jetten \& Wohl, 2012; Lucas et al., 2014). As such, we examined whether collective angst is a mechanism by which the appraisals of an attack by ISIS increase prejudice towards Muslims.

All materials and data from the presented research (including items and scales not considered in the present research) as well as supplemental analyses (see footnotes) are publically available via Open Science Framework (OSF): $\underline{\text { https://osf.io/gu8bx/ }}$

\section{Studies $1 \mathrm{a}$ and $1 \mathrm{~b}$}

\section{Method}

Participants. In Study 1a, we recruited 155 self-identified supporters of the Parti Québécois residing in Québec, Canada. One participant was excluded because he was residing in Canada for less than one year. Also, 18 participants were excluded because they had missing 
data. Thus, 136 participants (120 men and 16 women) were included in the analyses for Study 1a. They ranged in age from 16 to 80 years $(M=47.06, S D=17.60)$.

In Study 1b, we recruited 245 self-identified Lebanese-Christians residing in Lebanon. The data of 43 participants were excluded because they only provided demographic information (i.e., they did not respond to any of the questionnaires). In addition, the data of 67 participants were excluded due to missing data on the key measures. The remaining 135 participants (111 men and 22 women; two did not report their gender) were included in the analyses for Study $1 \mathrm{~b}$. Participants ranged in age from 18 to 75 years $(M=38.46, S D=14.17)$.

The minimum sample size for Studies $1 \mathrm{a}$ and $1 \mathrm{~b}$ was determined from a power analysis of a multiple linear regression analysis. Using $\mathrm{G}^{*}$ Power version 3.1 (Faul, Erdfelder, Buchner, \& Lang, 2009), we determined that a minimum of 89 participants would be needed to detect a small effect size with $95 \%$ confidence. Thus, Studies $1 \mathrm{a}$ and $1 \mathrm{~b}$ were adequately powered.

Procedure. Participants were recruited via a Facebook advertisement. In Study 1a, the advertisement was only displayed (in French) to people who indicated on their Facebook profile that they were Québécois, currently living in Québec, and were "Fans" of the Parti Québécois Facebook page as well as any of a variety of Parti Québécois politicians (e.g., Pauline Marois). The same procedure was used in Study 1b, where the advertisement was only displayed (in Arabic) to people who indicated on their Facebook profile that they were Lebanese, Christian, residing in Lebanon, and were "Fans" of any of a variety of Lebanese-Christian political parties. Participants who clicked on the advertisement were automatically directed to the consent form for the online study. Upon granting consent, participants completed a battery of questionnaires. At the end of the study, they were debriefed and entered into a lottery for one of thirty CDN \$10 gift cards for a local coffee shop (in Study 1a) or Amazon.com gift cards (Study 1b). 
Materials. All materials were initially constructed in English. In Study 1a, they were then translated into French by a member of the research team who is Québécois (Caouette) and verified by another Québécois colleague. Materials in Study 1b were translated to Arabic by a professional, certified translator in Lebanon. Prior to questionnaire battery, participants completed basic demographic items (e.g., age, sex).

Group identification. In Study 1a, participants responded to three items $(\alpha=.93)$ that were adapted from Cameron (2004) to assess their degree of identification with Québécois. Items were "I feel strong ties to other Québécois," "Being a Québécois is an important part of my selfimage," and "In general, I'm glad to be a Québécois." Responses to the three items were anchored at 1 (strongly disagree) and 7 (strongly agree). The responses were averaged such that higher scores indicated stronger identification with Québécois. In Study 1b, participants completed the same three items that we adapted for the Lebanese-Christian context ( $\alpha=.76$; e.g., "I feel strong ties to other Lebanese Christians"). These items were included to verify that participants in each sample, on average, identified with their group - a pre-condition for the experience of group-based emotions (Smith, 1993).

Appraisals of harm. In Study 1a, 12 items were constructed to assess participants' appraisal of potential harm to Québécois culture and identity (see Table 1 for a list of items). Four items $(\alpha=.94)$ assessed the perceived likelihood that Québécois culture and identity will be harmed if the French language disappeared in Québec. These items were anchored at 0 (not likely at all) and 10 (highly likely). Four items $(\alpha=.97)$ assessed the perceived severity of harm to Québécois culture and identity if the French language disappeared in Québec. These items were anchored at 0 (not at all harmful) and 10 (extremely harmful). Lastly, four items $(\alpha=.92)$ assessed the perceived efficacy of Québécois to protect the French language in Québec as well as 
Québécois culture and identity. These items were anchored at 0 (cannot do at all) and 10 (highly certain can do). In Study $1 \mathrm{~b}$ the items were for the Lebanese-Christian context. Specifically, they completed items measuring harm probability ( $\alpha=.84$; e.g., "How likely do you think it is that Lebanese Christians will be harmed if Islamic extremist groups invaded Lebanon”), harm severity ( $\alpha=.91$; e.g., "How harmful do you think that it will be for Lebanese Christians if Islamic extremist groups invaded Lebanon"), collective efficacy ( $\alpha=.93$; e.g., "How confident are you in the ability of Lebanese Christians to prevent Islamic extremist groups from invading Lebanon").

Collective angst. Five items $(\alpha=.76)$ assessed participants' concern for the future of Québécois culture and identity (adapted from Wohl et al., 2011). In Study 1a, items were "I feel anxious about the future of Québécois culture and identity," "I feel confident that Québécois culture and identity will survive" (reverse coded), "I feel secure about the future of Québécois culture and identity" (reverse coded), "I feel that Québécois culture and identity will always thrive" (reverse coded), and "I feel concerned that the future vitality of Québécois culture and identity is in jeopardy." Responses to the five items were anchored at 1 (strongly disagree) and 7 (stronlgy agree). In Study 1b, these items measured concern for the future of Lebanese Christians ( $\alpha=.85$; e.g., "I feel anxious about the future of Christians in Lebanon").

\section{Results}

Descriptive statistics and correlations for all variables in Studies 1a and $1 \mathrm{~b}$ are reported in Table 2. For Study 1a, the sample average of group identification was above the midpoint of the response scale, $t(132)=24.63, p<.001$. Likewise, the sample average of group identification in Study $1 \mathrm{~b}$ was above the midpoint of the response scale, $t(124)=14.40, p<.001$. These results 
suggest participants, in large, identified as either Québécois (Study 1a) or as Lebanese-Christian (Study 1b).

Factor structure of harm appraisals. A principal components analysis with oblimin rotation was conducted to examine whether participants' appraisals of harm probability, harm severity, and collective efficacy can be distinguished empirically. We used an oblimin rotation because we expected three correlated components to emerge from the principal components analysis. As expected, in Study 1a, three components were extracted (see Table 1) each with an Eigenvalue greater than 1. Items measuring harm severity loaded on the first factor, which explained $51.79 \%$ of the variance. Items measuring collective efficacy loaded onto the second factor, which explained an additional $23.49 \%$ of the variance. Items for harm probability loaded onto the third factor, which explained an additional $11.59 \%$ of the variance. None of the items cross-loaded on other factors. Importantly, results from a parallel analysis - a statistical procedure to determine the number of components to retain from principal components analyses (O’Connor, 2000) — involving 5000 random draws from the data indicated that retaining three components was the optimal solution.

Likewise, in Study 1b, three factors emerged from the principal components analysis each with an Eigenvalue greater than 1. However, one harm probability item loaded on both the harm probability factor $(B=.35)$ and harm severity factor $(B=.36)$. We decided to keep this item so that the scale used in Study $1 \mathrm{~b}$ was identical to the one used in Study 1a. Importantly, results from a parallel analysis confirmed that retaining three components was the optimal solution..

Predicting collective angst. Descriptive statistics and correlations between all variables in Studies 1a and 1b are in Table 2. In line with our hypotheses, appraisals of higher harm probability and higher harm severity were both associated with greater expressed feelings of 
collective angst whereas higher collective efficacy was associated with less collective angst (see

Table 2). Not surprisingly, although the three appraisals are distinct from each other, they were intercorrelated (see Table 2). Thus, we explored whether any or all appraisals uniquely predict collective angst. ${ }^{1,2}$

In Study 1a, a multiple linear regression showed that all three appraisals together accounted for $33 \%$ of the variance in collective angst, $R^{2}=.33, F(3,132)=21.86, p<.001$. As expected, higher harm severity uniquely predicted greater collective angst $(B=.31, t=4.67$, $p<.001$, and $95 \%$ CI $[.18, .43])$ and higher collective efficacy uniquely predicted less collective angst $(B=-.26, t=-6.53, p<.001$, and 95\% CI [-.34, -.18]). However, harm probability did not uniquely predict collective angst $(B=.04, t=.89, p=.38$, and 95\% $[-.05, .13])$. Likewise, in Study $1 \mathrm{~b}$, the appraisals together accounted for $50 \%$ of the variance in collective angst, $R^{2}=.50, F(3$, $131)=44.56, p<.001$. In line with expectations, higher harm probability uniquely predicted greater collective angst $(B=.21, t=5.56, p<.001$, and 95\% CI $[.14, .30])$ and higher collective efficacy uniquely predicted less collective angst $(B=-.20, t=-5.38, p<.001$, and 95\% CI [-.28, .13]). However, higher harm severity did not uniquely predict collective angst $(B=.05, t=1.30$, $p=.20$, and $95 \%$ CI $[-.03, .14])$.

\section{Discussion}

\footnotetext{
${ }^{1}$ We also examined whether the three appraisals interact to predict collective angst. All two-way and three-way interactions were not statistically significant except for a two-way interaction between harm severity and collective efficacy in Study 1a.

${ }^{2}$ Although the sample average for ingroup identification was high in both Studies $1 \mathrm{a}$ and $1 \mathrm{~b}(96.2 \%$ and $78.2 \%$ of the sample, respectively, had a score of five or more on the response scale), we assessed whether ingroup identification moderated the relationship between the appraisals and collective angst. To this end, we conducted two types of analyses. First, we examined whether ingroup identification moderated the relationship between each appraisal and collective angst. No interactions were statistically significant except for a two-way interaction between collective efficacy and ingroup identification in Study 1a. Second, we examined whether there was a four-way interaction between the three appraisals and ingroup identification. No interactions were statistically significant.
} 
The results of Study 1a and 1b supported our general hypothesis that appraisals of harm probability, harm severity, and collective efficacy are paramount for understanding when collective angst will be experienced. As expected, appraisals of higher harm probability, higher harm severity, and lower collective efficacy were each significantly associated with greater collective angst. We also found that a large portion of variance in collective angst was accounted for when the three appraisals were used (together) as predictors of this group-based emotion.

Interestingly, in Study 1a, harm severity and collective efficacy both predicted unique variance in collective angst, but this was not the case for harm probability. Similarly, in Study 1b, harm probability and collective efficacy predicted unique variance in collective angst, but this was not the case for harm severity. These inconsistent findings may be due to how we measured harm probability and harm severity. More specifically, harm probability was measured as the perceived probability that harm will occur to the ingroup should the threatening event occur whereas harm severity was measured as the perceived severity of harm to the ingroup should the threatening event occur. Although items measuring harm probability and harm severity could be distinguished empirically, they may have measured two different facets of perceived harmfulness to the ingroup. The reason is that harm probability was measured as the perceived likelihood that the ingroup would be harmed should the threatening event occur and not simply as the perceived likelihood of the threatening event occurring. In this light, it is not surprising why harm probability (in Study 1a) and harm severity (in Study 1b) were not unique predictors of collective angst. To address this issue, we conducted two additional studies (Studies $2 \mathrm{a}$ and $2 \mathrm{~b}$ ) in which harm probability was assessed via participants' perceived likelihood that the threatening event will occur.

\section{Studies $2 \mathrm{a}$ and $2 \mathrm{~b}$}


Although Studies 1a and 1b provided support for our general hypothesis about collective angst's antecedent appraisals, these studies were correlational, which limits causal inferences. As such, in Studies 2a and 2b, we manipulated the three appraisals (harm probability, harm severity, and collective efficacy) to assess their unique contributions to collective angst. To do so, we used the threat of a terrorist attack on American soil by ISIS to evoke collective angst and manipulated the probability of the ISIS terrorist attack occurring, the severity of the harm that would be experienced by Americans, and the efficacy of Americans to protect against an ISIS attack. We also extended our analysis to investigate a consequence of collective angst- (nonMuslim) American's prejudice against Muslims. It was hypothesized that the aforementioned appraisals of threat would heighten collective angst, in turn, increasing reported prejudice toward Muslims.

\section{Method}

Participants. In Study 2a, we recruited 506 Americans residing in the Unites States via Amazon's Mechanical Turk (MTurk). The data of 42 participants were excluded from the analyses because they indicated that our manipulations were not authentic $(n=26)$, failed two or more attention checks $(n=10)$, did not complete questionnaires measuring the dependent variables $(n=4)$, were Muslim $(n=1)$, or guessed the study aim $(n=1)$. Thus, the data of 464 participants (311 men and 152 women; one did not report gender) were included in the analyses for Study 2a. Participants ranged in age from 18 to 74 years $(M=31.93, S D=10.66)$.

In Study 2b, we recruited 550 Americans residing in the Unites States via MTurk. The data of 81 participants were excluded from the analyses because they did not provide consent to use their data $(n=38)$, failed two or more attention checks $(n=6)$, indicated that our manipulations were not authentic $(n=3)$, did not complete questionnaires measuring the dependent variables 
$(n=3)$, were not born in the United States $(n=2)$, were Muslim $(n=1)$, were not an American citizen $(n=1)$, or were not currently residing in America $(n=1)$. We also excluded participants who indicated that they participated in a previous study about ISIS ( $n=26)$ to reduce the possibility of including participants from Study $2 \mathrm{a}$ in Study 2b. Thus, the data of 469 participants (302 men and 167 women) were included in the analyses. Participants ranged in age from 18 to 71 years $(M=33.22, S D=10.94)$.

The minimum sample size for Studies $2 \mathrm{a}$ and $2 \mathrm{~b}$ was determined from a power analysis of a main effects ANOVA. Using $G^{*}$ Power software, we determined that a minimum of 404 participants would be needed to detect a small to moderate effect size with $95 \%$ confidence. Thus, Studies 2A and 2B were adequately powered.

Procedure and Materials. Participants in Studies 2a and $2 \mathrm{~b}$ were directed to the online study through an announcement on MTurk. The announcement indicated that we were seeking American citizens currently living in the U.S. for their opinions about the battle against ISIS. After providing informed consent, participants completed demographic questions followed by a 12-item group identification questionnaire (Cameron, 2004) that measured the extent to which they identify with Americans (Study 2a: $\alpha=.92$; Study 2b $\alpha=.94$ ). Participants were then randomly assigned to one of eight experimental conditions in which they read a news article ostensibly about a Pentagon Press Release entitled "ISIS Terrorist Operations in the U.S." (see Appendix A). A $2 \times 2 \times 2$ factorial design was employed to examine the independent effects of harm probability (low vs. high), harm severity (low vs. high), and collective efficacy (low vs. high) on collective angst.

In the high collective angst condition (i.e., high harm probability, high harm severity, and low collective efficacy), the news article indicated that the probability of terrorist attacks by ISIS 
is high and that ISIS is likely to attack America in the near future. The news article also indicated that an ISIS attack will severely harm the American people and severely damage American infrastructure. In addition, the article indicated that America has little ability to protect itself from ISIS terrorist attacks. In the low collective angst condition (i.e., low harm probability, low harm severity, and high collective efficacy), the news article indicated that the probability of terrorist attacks by ISIS is low and that ISIS is unlikely to attack America in the near future. The article also indicated that an ISIS attack will not harm the American people and cause little to no damage to America's infrastructure. Moreover, the article indicated that America has the ability to protect itself from ISIS terrorist attacks. In the remaining six conditions, participants read a news article that involved the remaining possible combinations of harm probability, harm severity, and collective efficacy (see Appendix A).

After reading the news article, all participants completed three manipulation check questions that assessed harm probability ("How likely you think that ISIS will attack the United States in the near future"), harm severity ("How harmful you think that an attack by ISIS on American soil will be for the United States"), and collective efficacy ("How confident you are in the ability of the United States to stop attacks by ISIS on American soil"). Akin to the previous studies, participants responded on 11-point scales ranging from 0 to 10 . Participants then completed a measure of collective angst about the future of the U.S. (Study $2 \mathrm{a}: \alpha=.83$; Study $2 \mathrm{~b}$ : $\alpha=.84$; e.g., "I feel anxious about the future of the United States") followed by a three-item measure that assessed prejudicial attitudes towards Muslims (adapted from Pettigrew \& Meertens, 1995). These items were: "I would not like to have Muslims as my neighbors," "I would accept a suitably qualified Muslim as my boss" (reverse coded), and "If I were single, I would consider marrying a Muslim person" (reverse coded). Responses were anchored at 1 
(strongly disagree) and 7 (strongly agree) and were averaged to form a prejudice towards Muslims scale (Study 2a: $\alpha=.80$; Study 2b: $\alpha=.77$ ). At the end of the study, all participants were debriefed, compensated U.S. \$0.50, and consent was sought to use their data (all participants consented).

\section{Results}

The sample average of group identification in Study 2a $(M=4.88, S D=1.06)$ was above the midpoint of the response scale, $t(455)=17.69, p<.001$. Likewise, the sample average of group identification in Study $2 \mathrm{~b}$ was above the midpoint of the response scale $(M=4.76, S D=$ $1.19), t(460)=13.82, p<.001$. These results suggest that participants, in large, identified as American.

Manipulation checks. In Study 2a, participants in the high harm probability conditions $(M=6.02, S D=2.88)$ reported higher likelihood that ISIS will attack America compared to participants in the low probability conditions $(M=4.22, S D=2.55), t(461)=7.10, p<.001, d=.66$. Those in the high harm severity conditions $(M=6.82, S D=2.78)$ viewed an attack by ISIS as more harmful to America compared to participants in the low harm severity conditions $(M=5.43$, $S D=2.61), t(462)=5.43, p<.001, d=.50$. Lastly, participants in the high collective efficacy conditions $(M=7.61, S D=2.30)$ reported that America has greater ability to stop an attack by ISIS compared to participants in the low collective efficacy conditions $(M=7.25 S D=2.51)$. This difference trended towards statistical significance, $t(462)=1.63, p=.10, d=.15$.

Likewise, in Study $2 b$, participants in the high harm probability conditions $(M=6.54$, $S D=2.81$ ) reported higher likelihood that ISIS will attack America compared to participants in the low probability conditions $(M=4.73, S D=2.81), t(467)=6.99, p<.001, d=.64$. Those in the high harm severity conditions $(M=6.77, S D=2.78)$ viewed an attack by ISIS as more harmful to 
America compared to participants in the low harm severity conditions $(M=5.45, S D=2.67)$, $t(466)=5.20, p<.001, d=.48$. Lastly, participants in the high collective efficacy conditions $(M=7.46, S D=2.61)$ reported that America has greater ability to stop an attack by ISIS compared to participants in the low collective efficacy conditions $(M=7.00, S D=2.40), t(467)=2.00, p=.04$, $d=.18$.

Predicting collective angst. As in Studies $1 \mathrm{~A}$ and 1B, we used a multiple linear regression analysis to examine whether the appraisals uniquely predict collective angst. In Study 2A, harm probability $(B=.26, t=2.44, p<.05$, and 95\% CI $[.05, .48])$, harm severity $(B=.36$, $t=3.37, p<.01$ and $95 \%$ CI $[.15, .58])$, and collective efficacy $(B=-.30, t=-2.75, p<.01$, and 95\% CI [-.51, -.08]) each uniquely predicted collective angst, $R^{2}=.05, F(3,460)=8.39, p<.001$. Likewise, in Study 2B, harm probability $(B=.25, t=2.27, p<.05$, and 95\% CI $[.03, .46])$, harm severity $(B=.34, t=3.11, p<.01$, and 95\% CI $[.12, .56])$, and collective efficacy $(B=-.29, t=-2.71$, $p<.01$, and 95\% CI [-.51, -.08]) each uniquely predicted collective angst, $R^{2}=.04, F(3,465)=7.23$, $p<.001$. Together, these findings support our general hypothesis and demonstrate that appraisals of high harm probability, high harm severity, and low collective efficacy independently contribute to increasing collective angst. ${ }^{3,4}$

We also conducted follow-up comparisons in Studies $2 \mathrm{a}$ and $2 \mathrm{~b}$ to confirm that participants in the high collective angst condition (i.e., high harm probability, high harm severity, and low collective efficacy) reported more collective angst relative to participants in the low collective angst condition (i.e., low harm probability, low harm severity, and high collective

\footnotetext{
${ }^{3}$ As in Studies 1a and 1b, we conducted additional analyses to examine whether the three appraisals interact to predict collective angst. No interactions were statistically significant except for a two-way interaction between harm probability and harm severity in Study $2 b$.

${ }^{4} \mathrm{As}$ in Studies 1a and 1b, we examined whether ingroup identification moderates the relationship between the appraisals and collective angst. No interactions were statistically significant in either Study $2 \mathrm{a}$ or $2 \mathrm{~b}$.
} 
efficacy) and participants in the remaining six conditions. In both studies, we collapsed across the remaining six conditions because there was no omnibus difference in collective angst, $F(5$, $345)=1.90, p=.09$ and $F(6,354)=1.68, p=.13$, respectively. We refer to this combination of conditions as the moderate collective angst condition. As expected, in Study 2a, participants in the high collective angst condition reported more collective angst $(M=3.76, S D=1.39)$ relative to participants in the moderate collective angst condition $(M=3.20, S D=1.13), t(404)=3.42, p=.001$, $d=.44$, and participants in the low collective angst condition $(M=2.86, S D=1.19), t(116)=3.75$, $p<.001, d=.71$. Also, participants in the moderate collective angst condition reported more collective angst compared to participants in the in the low collective angst condition, $t(402)=2.06, p=.04, d=.29$.

The same pattern of findings emerged in Study 2b. Participants in the high collective angst condition reported more collective angst $(M=4.00, S D=1.20)$ relative to participants in the moderate collective angst condition $(M=3.25, S D=1.21), t(407)=4.05, p<.001, d=.62$, and participants in the low collective angst condition $(M=2.86, S D=1.06), t(106)=5.24, p<.001$, $d=1.01$. Also, participants in the moderate collective angst condition reported more collective angst compared to participants in the low collective angst condition, $t(419)=2.37, p=.01, d=.34$. In sum, the findings support the hypothesis that participants will feel the greatest collective angst when they appraise a threat to the ingroup as having high harm probability and high harm severity, and appraise the ingroup as having low collective efficacy to protect itself from the threat.

Mediation analysis for prejudice towards Muslims. Our next goal was to test a mediation model. We examined whether collective angst would mediate the effect of experimental threat conditions (high, moderate, and low) on prejudice towards Muslims. These 
comparisons were included in the mediation model as independent variables using two dummy coded variables (the low threat condition was the reference group). Collective angst was included as the mediator variable and prejudice towards Muslims was included as the dependent variable. Across experimental conditions, participants reported some prejudice towards Muslims in Study 2a $(M=3.06, S D=1.51)$ and Study $2 \mathrm{~b}(M=3.03, S D=1.46)$. In addition, collective angst was positively associated with prejudice towards Muslims in Study $2 \mathrm{a}(r=.10, p=.02)$ and Study $2 \mathrm{~b}$ $(r=.11, p=.02)$. To conduct the mediation analysis, we used the PROCESS macro (model 4) developed by Hayes (2013) to estimate all parameters. PROCESS was used to obtain 95\% biascorrected bootstrapped confidence intervals (with 5000 iterations). All variables were meancentered except for the mediator and dependent variables. As such, parameter estimates are unstandardized.

As shown in Figure 1, participants in the high collective angst condition reported more collective angst compared to participants in the low collective angst condition. In turn, greater collective angst predicted greater prejudice towards Muslims. As expected, in Study 2a, participants in the high threat condition reported more prejudice towards Muslims relative to participants in the low threat condition via their increased collective angst, indirect effect $=.13$, $95 \%$ CI $[.02, .28]$. The same pattern of findings emerged for the comparison between participants in the moderate and low threat conditions. Specifically, participants in the moderate threat condition reported more prejudice towards Muslims relative to participants in the low threat condition via their increased collective angst, indirect effect $=.04,95 \%$ CI $[.002, .14]$.

Virtually identical results were observed in Study 2b (see Figure 1). As expected, participants in the high threat condition reported more prejudice towards Muslims relative to participants in the low threat condition via their increased collective angst, indirect effect=.17, 
95\% CI $[.04, .33]$. The same pattern of findings emerged for the comparison between participants in the moderate and low threat conditions. Specifically, participants in the moderate threat condition reported more prejudice towards Muslims relative to participants in the low threat condition via their increased collective angst, indirect effect $=.06,95 \% \mathrm{CI}[.01, .15]$. Thus, collective angst mediated the effect of the experimental threat manipulations on prejudice towards Muslims.

\section{Discussion}

The results of Studies $2 \mathrm{a}$ and $2 \mathrm{~b}$ provide causal support for the hypothesis that appraisals of harm probability, harm severity, and collective efficacy predict collective angst. Importantly, we found that the appraisals independently contributed to the experience of collective angst. That is, we observed that Americans felt the most collective angst when they appraised the terrorist attack as likely to harm and severely hurt America, and appraised America as having little or no ability to protect against a terrorist attack. In contrast, Americans felt the least collective angst when they appraised the terrorist attack as unlikely to harm and mildly hurt America, and appraised America as having the ability to protect against a terrorist attack. As well, Americans reported experiencing some collective angst when either harm probability or harm severity was high, or collective efficacy was low. These results are consistent with the associations between the appraisals and collective angst observed in our previous studies (Studies 1a and 1b).

We also found that the observed differences in collective angst mediated the effect of the experimental manipulation of the appraisals on prejudice towards Muslims. Specifically, nonMuslim Americans in the high collective angst condition (high harm probability, high harm severity, and low collective efficacy) reported more prejudice towards Muslims relative to nonMuslim Americans in the low collective angst condition (low harm probability, low harm 
severity, and high collective efficacy) and this effect was mediated by the increase in collective angst. We observed the same mediation when comparing participants in the moderate and low collective angst conditions. Thus, resulted observed in both Study $2 \mathrm{a}$ and Study $2 \mathrm{~b}$ replicate and extend Study 1a and Study 1b by showing that appraisals of harm probability, harm severity, and collective efficacy can have social consequences via their influence on feelings of collective angst.

\section{General Discussion}

There is a growing body of research that has demonstrated intergroup appraisals are important for understanding how people feel about themselves and their social identities (e.g., Outten, Schmitt, Garcia, \& Branscombe, 2009) and important for regulating intergroup attitudes and behaviour (e.g., Leach, Iyer, \& Pedersen, 2007; Mackie, Devos, \& Smith, 2000; van Zomeren, Spears, Fischer, \& Leach, 2004). Herein, we extended this line of inquiry by applying the cognitive model of anxiety (Beck et al., 1985; Clark \& Beck, 2010) to the group level to understand the appraisals that regulate collective angst. Thus, the current research adds to a growing body of research in which traditionally individual-level theories have been successfully applied to the group-level.

In specific, the current research provides two novel contributions to the literature on the antecedents of collective angst. First, our research extends our understanding of the appraisals that constitute perceived threats to the ingroup's future vitality. While a large body of research has established that the mere perception of distinctiveness and extinction threats to the ingroup's future vitality are key sources of collective angst (Wohl et al., 2012), no research has examined the appraisals that constitute these threats. In Study 1a, we measured Parti Québécois supporters' appraisals of a distinctiveness threat (i.e., loss of the French language in Québec) and found that 
appraisals of harm probability, harm severity, and collective efficacy were empirically distinct. Importantly, we also found that appraisals of higher harm probability, higher harm severity, and lower collective efficacy were each moderately associated with greater expressed collective angst. Study $1 \mathrm{~b}$ replicated the findings of Study $1 \mathrm{a}$ in the context of an extinction threat (Lebanese-Christians' appraisals of Islamic extremist groups invading their lands). As such, the findings of Studies 1a and 1b enhance our understanding of the appraisals underlying perceived threats to the ingroup's future vitality. These findings dovetail with a previous study comparing the perception of symbolic and extinction threats on collective angst (see Study 1 in Wohl et al., 2010). Indeed, this study found that symbolic and extinction threats both evoked collective angst to a similar extent and both evoked more collective angst relative to a control group. In light of the current research, it may be fruitful to explore possible differences between symbolic and extinction threats using the appraisals examined in the present research.

Second, our research extends our understanding of how appraisals evoke collective angst. Consistent with the cognitive model of anxiety (Beck et al., 1985; Clark \& Beck, 2010), we observed in Studies $2 \mathrm{a}$ and $2 \mathrm{~b}$ that collective angst was an additive function of the three theorized appraisals: harm probability, harm severity, and collective efficacy. Specifically, Americans reported the most collective angst when they were informed that ISIS was likely to attack America, that the ISIS attack would severely harm America, and that America does not have the ability to protect against an ISIS attack. In contrast, Americans reported the least collective angst when they were informed that ISIS was unlikely to attack America, that any ISIS attack would inflict little harm to America, and that America has the ability to protect against an ISIS attack. This observed difference in collective angst was large like prior research that involved manipulating either probability of harm posed by a threat (see Study 1 in Wohl et al., 
2009), severity of harm posed a threat (see Study 1 in Wohl et al., 2010), or collective efficacy to prevent a threat from occurring (see Study 2 in Halperin et al., 2013) relative to a control condition in which the threat was absent. However, Americans still reported some collective angst when they were informed either that ISIS was likely to attack America, or that an attack by ISIS would inflict severe harm to America, or that America lacks the ability to protect against an ISIS attack. Their level of collective angst was greater than Americans who experienced the least collective angst, but less than Americans who experienced the most collective angst. Thus, the results of Studies $2 \mathrm{a}$ and $2 \mathrm{~b}$ demonstrate that the appraisals have a cumulative effect on collective angst and that collective angst can be up- or down-regulated via appraisals of harm probability, harm severity, and collective efficacy.

Furthermore, we observed in Studies $2 \mathrm{a}$ and $2 \mathrm{~b}$ that the appraisals can affect a socially consequential outcome via their influence on collective angst. Specifically, we found that the experimental manipulation of the appraisals predicted more prejudiced attitudes towards Muslims to the extent that collective angst for the future of America was aroused. This finding extends prior research that has investigated the effects of perceived terrorist threat on prejudice as a function of perceived collective efficacy (see Study 1 in Greenaway, Louis, Hornsey, \& Jones, 2014). More specifically our findings suggest that feelings of collective angst may help explain why people who perceive that their group is under threat become more prejudiced when they also believe that their group has low efficacy to protect itself from the perceived threat. As well, our findings are consistent with prior research demonstrating that collective angst is a mediating mechanism linking perceptions of existential threat with an array of attitudes and behaviours aimed at securing the ingroup's future (for a review see, Wohl et al., 2012). Importantly, however, the added value of our appraisal-based approach to collective angst is that 
appraisals of harm probability, harm severity, and collective efficacy can be used to up- or downregulate feelings of collective angst as needed to facilitate actions to protect the ingroup. Moreover, because the current research only focused on prejudice as an outcome of collective angst, future research may be served by examining whether collective angst mediates the influence of the three appraisals on other outcomes, such as willingness to engage in actions to protect the future existence of the ingroup.

An important direction for future research is to examine whether evoking collective angst (via the appraisals) produces a biological response analogous to anxious arousal. Doing so will bring research on collective angst closer to the broader threat and defense literature, which has largely focused on anxious arousal stemming from individual-level threats to the self (e.g., mortality salience and threats to self-esteem; see Jonas, McGregor, Klackl et al., 2014). While no prior research has examined the biological markers of collective angst, prior research suggests that collective angst may elicit a physiological stress response. For example, Scheepers and colleagues (Scheepers, 2009; also see Scheepers, Ellemers, Sintemaartensdijk, 2009) have found that high status group members who perceived a possible loss of their status had a cardiovascular stress pattern whereas low status group members who perceived a possible improvement in their status had a cardiovascular challenge pattern. It is possible that participants in this line of research appraised the perceived changes in the intergroup hierarchy in terms of harm probability, harm severity, and collective efficacy. Future research may do well to examine this possibility and the biological markers of anxious arousal underpinning collective angst.

The current research may also contribute to the literature on conflict resolution in intractable conflicts. In his review, Halperin (2014) proposed that to encourage conciliatory attitudes and reparations between rival groups, it is necessary to alter appraisals associated with 
negative emotions that are considered barriers to peace. Like other negative emotions (e.g., anger; see Halperin, 2011), collective angst has been identified as a barrier to peace negotiations (Halperin et al., 2013; Wohl et al., 2016). Thus, by elucidating the appraisals that evoke collective angst, conflict resolution scholars and practitioners may have new tools to downregulate collective angst. For instance, interventions (e.g., focus groups) can be designed to encourage ingroup members to appraise the outgroup as unlikely to harm the ingroup, appraise the harm that may be experienced at the hands of the outgroup as benign, and appraise the ingroup as having the collective efficacy to protect itself from the outgroup. When ingroup members appraise the outgroup and their ability in this way, they may be more willing to compromise in peace negotiations (see also Maoz \& McCauley, 2009). In sum, the current findings open an important avenue for future research - one in which the down-regulation of collective angst via the appraisals is assessed as a facilitator of conflict resolution.

Our research may also shed light on the appraisals that constitute perceived threats to the value of the ingroup's identity (Branscombe, Ellemers, Spears, \& Doosje, 1999). Such threats involve perceptions that the ingroup's value is being undermined. It is also possible that ingroup members may appraise value threats in terms of harm probability, harm severity, and collective efficacy when the threat also affects the future vitality of the ingroup. There is some evidence for this idea. For instance, Outten, Schmitt, Miller, and Garcia (2012; Study 2) showed that White Canadians who were informed that they will soon no longer be the numerical majority in Canada reported greater anger and fear toward minorities as well as greater sympathy towards White Canadians. Threat was assessed in part via agreement that White Canadians will have little influence on Canadian society in the future - a measure of collective efficacy concerns. Although probability of harm and severity of harm due to ethnic diversity in Canada were not 
directly measured in Outten and colleagues' study, White Canadians who believed they would be a numerical minority in the future also appraised greater ethnic diversity as more threatening. This appraisal may reflect beliefs that increasing ethnic diversity will likely harm White Canadians (harm probability) and inflict severe damage to White Canadians (harm severity). Thus, appraisals of harm probability, harm severity, and collective efficacy may be useful for research on threats that undermine the perceived value of the ingroup, particularly when such threats also affect the future vitality of the ingroup. In such situations, collective angst is likely to be at the heart of group-level behaviour.

A possible limitation of the current research is our method of recruitment. We recruited Parti Québécois supporters in Study 1a and Lebanese-Christians in Study 1b on Facebook, and recruited Americans in Studies 2a and 2b on MTurk. As such, participants in our four studies selected themselves (i.e., self-selection bias), which may limit the generalizability of our findings. While there is evidence that samples recruited from non-commercial internet web sites (Gosling, Vazire, Srivastava, \& John, 2004) and from MTurk (Buhrmester, Kwang, \& Gosling, 2011) are more demographically diverse than samples recruited using more traditional methods, we do not know how representative each of our samples are of their respective general population. With that said, the present research had several strengths that minimized the impact of our recruitment method. Specifically, a large sample was obtained for each of the four studies, key findings replicated across the studies, and those findings were observed in a number of different real-world intergroup contexts.

\section{Conclusions}

In the current research, we were able to apply the cognitive model of anxiety (Beck et al., 1985) to the intergroup level in order to examine when (and how much) collective angst is 
experienced in the face of intergroup threat. We found that perceived threats to the ingroup's future vitality evoke the greatest amount of collective angst when they are appraised as likely to yield harm to the ingroup, the harm that may be experienced is appraised as being severe, and the ingroup is appraised as lacking the collective efficacy to protect itself from intergroup threat. Understanding the specific threat appraisals that evoke collective angst and knowing that they can be manipulated provides a route to up- or down-regulate this emotion-knowledge that may be used to increase the pro-social and decrease the anti-social outcomes of collective angst. 


\section{References}

Bandura, A. (1988). Self-efficacy conception of anxiety. Anxiety Research: An International Journal, 1, 77-98. doi: 10.1080/10615808808248222

Bandura, A. (1997). Self-efficacy: The exercise of control. New York: Freeman.

Beck, A. T., Emery, G., \& Greenberg, R. (1985). Anxiety disorders and phobias: A cognitive perspective. Basic Books.

Blascovich, J., \& Tomaka, J. (1996). The biopsychosocial model of arousal regulation. In M. Zanna (Ed.). Advances in experimental social psychology (Vol. 28, pp. 1-51). New York: Academic Press

Branscombe, N. R., Ellemers, N., Spears, R., \& Doosje, B. (1999). The context and content of social identity threats. In N. Ellemers, R. Spears, \& B. Doosje (Eds.), Social identity: Context, commitment, content (pp. 35-58). Oxford: Blackwell.

Buhrmester, M., Kwang, T., \& Gosling, S. D. (2011). Amazon's Mechanical Turk: A new source of inexpensive, yet high-quality, data? Perspectives on Psychological Science, 6, 3-5. doi: $10.1177 / 1745691610393980$

Cameron, J. (2004). A three factor model of social identity. Self and Identity, 3, 239-262. doi: $10.1080 / 13576500444000047$

Carver, C. S. (2015). Control processes, priority management, and affective dynamics. Emotion Review, 7, 301-307. doi: 10.1177/1754073915590616

Chandler, M. J., \& Lalonde, C. E. (1998). Cultural continuity as a hedge against suicide in Canada's First Nations. Transcultural Psychiatry, 35, 191-219. doi: $10.1177 / 136346159803500202$ 
Clark, D. A., \& Beck, A. T. (2010). Cognitive therapy of anxiety disorders: Science and practice. NY: Guilford Press.

Cohen, J., Cohen, P., West, S. G., \& Aiken, L. S. (2003). Applied multiple regression/correlation analysis for the behavioral sciences ( $3^{\text {rd }}$ ed.). New Jersey: Mahwah.

Dupuis, D. R., Porat, R., \& Wohl, M. J. A. (2015). Collective angst in intractable conflicts: How concern for the ingroup's future vitality shapes adversarial intergroup relations. In E. Halperin \& K. Sharvit (Eds.), The Social Psychology of Intractable Conflicts: Celebrating The Legacy of Daniel Bar-Tal (vol. 1, pp. 131-142). New York: Springer

Durkheim, E. (1951). Suicide. London: Simon \& Schuster.

Faul, F., Erdfelder, E., Buchner, A., \& Lang, A. G. (2009). Statistical power analyses using G*Power 3.1: Tests for correlation and regression analyses. Behavior Research Methods, $41,1149-1160$.

Gosling, S. D., Vazire, S., Srivastava, S., \& John, O. P. (2004). Should we trust web-based studies? A comparative analysis of six misconceptions about internet questionnaires. American Psychologist, 59, 93-104. doi: 10.1037/0003-066X.59.2.93

Greenaway, K. H., Louis, W. R., Hornsey, M. J., \& Jones, J. M. (2014). Perceived control qualifies the effects of threat on prejudice. British Journal of Social Psychology, 53, 422442. doi: 10.1111/bjso.12049

Halperin, E. (2014). Emotion, emotion regulation, and conflict resolution. Emotion Review, 6, 68-76. doi: $10.1177 / 1754073913491844$

Halperin, E. (2011). Emotional barriers to peace: Emotions and public opinions of Jewish Israelis about the peace process in the Middle East. Peace and Conflict, 17, 22-45. doi: $10.1080 / 10781919.2010 .487862$ 
Halperin, E., Porat, R., \& Wohl, M. J. A. (2013). Extinction threat and reciprocal threat reduction: Collective angst predicts willingness to compromise in intractable intergroup conflicts. Group Processes and Intergroup Relations, 16, 797-813. doi:

$10.1177 / 1368430213485994$

Hayes, A. (2013). Introduction to mediation, moderation, and conditional process analysis. New York: Guilford Press.

Jetten, J., \& Hutchison, P. (2011). When groups have a lot to lose: Historical continuity enhances resistance to a merger. European Journal of Social Psychology, 41, 335-343. doi: 10.1002/ejsp.779

Jetten, J., \& Wohl, M. J. A. (2012). The past as a determinant of the present: Historical continuity, collective angst, and opposition to immigration. European Journal of Social Psychology, 42, 442-450. doi: 10.1002/ejsp.865

Jonas, E., McGregor, I., Klackl, J., Agroskin, D., Fritsche, I., Holbrook, C., Nash, K., Proulx, T., \& Quirin, M. (2014). Threat and defense: From anxiety to approach. In J. M. Olson, \& M. P. Zanna (Eds.), Advances in Experimental Social Psychology (vol. 49, pp. 219-286). Burlington: Academic Press.

Lampinen, J. M., Odegard, T. N., \& Leding, J. K. (2004). Diachronic disunity. In D. R. Beike, J. M. Lampinen, \& D. A. Behrend (Eds.), The self in memory (pp. 227-253). New York: Psychology Press.

Lazarus, R. S., \& Folkman, S. (1984). Stress, appraisal, and coping. New York: Springer Publishing Company. 
Leach, C. W., Iyer, A., \& Pedersen, A. (2007). Angry opposition to government redress: When the structurally advantaged perceive themselves as relatively deprived. British Journal of Social Psychology, 46, 191-204. doi: 10.1348/014466606X99360

Lucas, T., Rudolph, C., Zhdanova, L., Barkho, E., \& Weidner, N., (2014). Distributive justice for others, collective angst, and support for exclusion of immigrants. Political Psychology, 35, 775-793. doi: 10.1111/pops.12204

Mackie, D. M., Devos, T. \&, Smith, E. R. (2000). Intergroup emotions: Explaining offensive action tendencies in an intergroup context. Journal of Personality and Social Psychology, 79, 602-616. doi: 10.10371/0022-3514.79.4.602

Maitner, A. T., Mackie, D. M., \& Smith, E. R. (2006). Evidence for the regulatory function of intergroup emotion: Implementing and impeding intergroup behavioral intentions. Journal of Experimental Social Psychology, 42, 720-728. doi:

10.1016/j.jesp.2005.08.001

Maoz. I. \& McCauley, C. (2009) Threat perceptions and feelings as predictors of Jewish-Israeli support for compromise with Palestinians. Journal of Peace Research, 46, 525-539. doi: $10.1177 / 0022343309334613$

Mashuri, A., \& Zaduqisti, E. (2015). The effect of intergroup threat and social identity salience on the belief in conspiracy theories over terrorism in Indonesia: Collective angst as a mediator. International Journal of Psychological Research, 8, 24-35.

Mols, F. \& Jetten, J. (2014). No guts, no glory: How framing the collective past paves the way for anti-immigrant sentiments. International Journal of Intercultural Relations, 43, 7486. doi: 10.1016/j.ijintrel.2014.08.014 
Mroue, B., \& Karam, Z. (2015, September 5). Alarmed by regional threat, Lebanon's Christians take up arms. The Globe and Mail. Retrieved from http://www.theglobeandmail.com/

O’Connor, B. P. (2000). SPSS and SAS programs for determining the number of components using parallel analysis and Velicer's MAP test. Behavior Research Methods, Instruments, \& Computers, 32, 396-402. doi: 10.3758/BF03200807

Outten, R. H., Schmitt, M. T., Garcia, D. M., \& Branscombe, N. R. (2009). Coping options: Missing links between minority group identification and psychological well-being. (2009). Applied Psychology, 58, 146-170. doi: 10.1111/j.1464-0597.2008.00386.x

Outten, R. H., Schmitt, M. T., Miller, D. A., \& Garcia, A. L. (2012). Feeling threatened about the future: Whites' emotional reactions to anticipated ethnic demographic changes. Personality and Social Psychology Bulletin, 38, 14-25. doi: 10.1177/0146167211418531

Parti Québécois leader Pauline Marois. (2012, July 23). Canadian Broadcast Corporation. Retrieved from http://www.cbc.ca

Pettigrew, T. F., \& Meertens, R. W. (1995). Subtle and blatant prejudice in Western Europe. European Journal of Social Psychology, 25, 57-75. doi: 10.1002/ejsp.2420250106

Rank, O. (1914). The Myth of the Birth of the Hero: A Psychological Interpretation of Mythology. (F. Robbins \& S. Jelliffe, Trans.). New York: Nervous \& Mental Disease Monograph Series no. 18. (Original work published 1909).

Reicher, S.D. \& Hopkins, N. (2001). Self and nation. London: Sage.

Riek, B. M., Mania, E. W., \& Gaertner, S. L. (2006). Intergroup threat and outgroup attitudes: A meta-analytic review. Personality and Social Psychology Review, 10, 336-353. doi: 10.1207/s15327957pspr1004_4 
Sani, F., Bowe, M., Herrera, M., Manna, C., Cossa, T., Miao, X., \& Zhou, Y. (2007). Perceived collective continuity: Seeing groups as entities that move through time. European Journal of Social Psychology, 37, 1118-1134. doi: 10.1002/ejsp.430

Sartre, J. P. (1956). Being and nothingness: An essay on phenomenological ontology. H. Barnes (Trans.). London: Methuen \& Col.

Smith, E. R. (1993). Social identity and social emotions: Toward new conceptualizations of prejudice. In D. M. Mackie \& D. L. Hamilton (Eds.), Affect, cognition, and stereotyping: Interactive processes in group perception (pp. 297-315). San Diego, CA: Academic Press.

Tomaka, J., Blascovich, J. Kelsey, R. M., \& Leitten, C. L. (1993). Subjective, physiological, and behavioral effects of threat and challenge appraisal. Journal of Personality and Social Psychology, 65, 248-260. doi: 10.1037/0022-3514.65.2.248Tomaka, J., Blascovich, J. Kibler, J., \& Ernest, J. M. (1997). Cognitive and physiological antecedents of threat and challenge appraisals. Journal of Personality and Social Psychology, 73, 63-72. doi: $10.1037 / 0022-3514.73 .1 .63$

Van Zomeren, M., Leach, C. W., \& Spears, R. (2012). Protesters as "passionate economists": A dynamic dual pathway model of approach coping with collective disadvantage. Personality and Social Psychology Review, 16, 180-199. doi: $10.1177 / 1088868311430835$

Van Zomeren, M., Spears, R., Fischer, A. H., \& Leach, C. W. (2004). Put your money where your mouth is! Explaining collective action tendencies through group-based anger and group efficacy. Journal of Personality and Social Psychology, 87,649-664. doi:

$10.1037 / 0022-3514.87 .5 .649$ 
Vlek, C., \& Stallen, P-J. (1980). Rational and personal aspects of risk. Acta Psychologica, 45, 273-300. doi: 10.1016/0001-6918(80)90038-4

Wohl, M. J. A., \& Branscombe, N. R. (2009). Group threat, collective angst and ingroup forgiveness for the war in Iraq. Political Psychology, 30, 193-217. doi: 10.1111/j.14679221.2008.00688.x.

Wohl, M. J. A., Branscombe, N. R., \& Reysen, S. (2010). Perceiving your group's future to be in jeopardy: Extinction threat induces collective angst and the desire to strengthen the ingroup. Personality and Social Psychology Bulletin, 36, 898-910. doi:

$10.1177 / 0146167210372505$

Wohl, M. J. A., Giguère, B., Branscombe, N. R., \& McVicar, D. N. (2011). One day we might be no more: Collective angst and protective action from potential distinctiveness loss. European Journal of Social Psychology, 41, 289-300. doi:10.1002/ejsp.773.

Wohl, M. J. A., King, M., \& Taylor, D. M. (2014). Expressions of political practice: Collective angst moderates politicized collective identity to predict support for political protest (peaceful or violent) among diaspora group members. International Journal of Intercultural Relations, 43,114-125. doi:10.1016/j.ijintrel.2014.08.020

Wohl, M. J. A., Porat, R., \& Halperin, E. (2016). Unfreezing cognition during intractable conflict: Does an external incentive for negotiating peace and (low levels of) collective angst increase information seeking? British Journal of Social Psychology, 55, 65-87. doi: 10.1111/bjso. 12121

Wohl, M. J. A., Squiers, E. C., \& Caouette, J. (2012). We were, we are, will we be? The social psychology of collective angst. Social and Personality Psychology Compass, 6, 379-391. doi: 10.1111/j.1751-9004.2012.00437.x 
Table 1.

Rotated factor loadings from an exploratory factor analysis of questionnaire items assessing participants' appraisals of harm probability, harm severity, and collective efficacy in Study 1 a.

\begin{tabular}{|c|c|c|c|}
\hline Questionnaire item & $\begin{array}{c}\text { Harm } \\
\text { severity }\end{array}$ & $\begin{array}{l}\text { Collective } \\
\text { efficacy }\end{array}$ & $\begin{array}{c}\text { Harm } \\
\text { probability }\end{array}$ \\
\hline \multicolumn{4}{|l|}{ How likely is it that Québécois culture and identity will be harmed if ... } \\
\hline ...the French language is not spoken by the majority of Québécois. & .99 & -.02 & -.03 \\
\hline ...the French language is not the first language in Québec. & .98 & .01 & .01 \\
\hline ...the French language is not safeguarded by Québécois. & .91 & .03 & .01 \\
\hline ...the French language loses its significance in Québec. & .89 & .01 & .04 \\
\hline \multicolumn{4}{|l|}{ How confident are you in the ability of the Québécois to ... } \\
\hline ...ensure that the French language is spoken by the majority of Québécois. & .03 & .91 & .03 \\
\hline ...safeguard Québécois culture and identity. & -.01 & .90 & -.06 \\
\hline ...prevent the French language from losing its significance in Québec. & -.09 & .89 & -.03 \\
\hline ...prevent the French language from losing its place as the first language of Québec. & .10 & .74 & .08 \\
\hline \multicolumn{4}{|l|}{ How harmful will it be for Québécois culture and identity if ... } \\
\hline ...the French language is not safeguarded by Québécois. & -.08 & -.04 & .99 \\
\hline ...the French language is not spoken by the majority of Québécois. & -.01 & .01 & .97 \\
\hline ...the French language is not the first language in Québec. & -.01 & .05 & .89 \\
\hline ...the French language loses its significance in Québec. & .21 & .01 & 68 \\
\hline
\end{tabular}

$N=136$. 
Table 2.

Descriptive statistics and correlations between all variables in Studies $1 \mathrm{a}$ and $1 \mathrm{~b}$.

\begin{tabular}{lccccccccc}
\hline Variable & $M$ & $S D$ & 1 & 2 & 3 & 4 & 5 & $M$ & $S D$ \\
\hline 1. Harm probability & 8.50 & 1.62 & - & $.40^{* *}$ & $-.46^{* *}$ & -.11 & $.63^{* *}$ & 6.15 & 3.09 \\
2. Harm severity & 8.95 & 1.53 & $.61^{* *}$ & - & $-.16^{\dagger}$ & -.07 & $.32^{* *}$ & 8.14 & 2.49 \\
3. Collective efficacy & 7.16 & 1.87 & $.20^{*}$ & $.29^{* *}$ & - & $.21^{*}$ & $-.58^{* *}$ & 5.66 & 3.00 \\
4. Group identification & 6.47 & 1.16 & .15 & $.30^{* *}$ & $.24 * *$ & - & $-.22^{*}$ & 5.69 & 1.13 \\
5. Collective angst & 4.31 & 1.09 & $.25^{* *}$ & $.34^{* *}$ & $-.35^{* *}$ & -.05 & - & 3.99 & 1.61
\end{tabular}

Note. Descriptive statistics and correlations for Study 1a appear below the diagonal and for Study $1 \mathrm{~b}$ above the diagonal.

${ }^{\dagger} p=.06 ; * p<.05 ; * * p<.01$. 


\section{Figure Caption}

Figure 1. Mediation model in Studies 2a and 2b with comparisons between appraisal manipulations as the independent variables, collective angst as the mediator variable, and prejudice towards Muslims as the dependent variable.

Note. Path coefficients are unstandardized. Coefficients before the slash are for Study 2a and coefficients after the slash are for Study $2 b$.

$* p<.05 ; * * p<.01$. 